\title{
MAX STIRNER E A CRÍTICA DA ECONOMIA POLÍTICA
}

Gerhard Senft

(Viena d'Áustria)

\section{Sobre a recepção da Economia Política}

Stirner começou logo no início da década de 1840 a familiarizar-se com a Economia Política. No contexto da Economia Política, considera-se que tudo aquilo que é relacionado com a economia assenta em desenvolvimentos sociais e políticos, cada constelação económica aparece como resultado dum processo histórico. Para a Economia Política, isto não tem só que ver com a procura de determinados regulamentos jurídicos ou descobertas empíricas, mas também com a formulação de normas objectivas para a política económica. Em Julho de 1842 foi publicado no jornal Leipziger Allgemeinen Zeitung um artigo de Stirner, no qual ele discutia o tema do comércio livre. Ele foi prosaico, não tomou de maneira nenhuma partido do juízo exaltado da sua época a favor das ideias do comércio livre, nem tão pouco se deu a conhecer como um opositor completo do proteccionismo (Stirner, 1976a). Os desentendimentos entre Friedrich Engels e Karl Marx a propósito de questões económicas só se viriam a instalar mais tarde: em Janeiro de 1844 completou Engels a sua obra "Umrisse einer Kritik der Nationalökonomie" (Engels, 1976), entre Abril e Agosto do mesmo ano escreveu Marx a sua obra "Ökonomisch-philosophischen Manuskripte" (Marx, 1981).

Ainda enquanto Stirner trabalhava para acabar a sua obra principal "Der Einzige und sein Eigentum", intensificou-se o seu desagrado com a Economia Política. Não foi por acaso que na obra de Stirner, que estava completa no verão de 1844, também apareceram temas da área do liberalismo económico. Enquanto nesse ano Stirner começou com a publicação da série "Die Nationalökonomen der Franzosen und Engländer", já ele tinha adquirido competências essenciais. Em 1845 foi publicado primeiro 
na editora Otto Wigand, em Leipzig, a obra de Jean Baptist Say "Cours complet d'économie politique pratique" em quatro volumes. Os quatro volumes seguintes foram preenchidos com a obra de Adam Smith "An Inquiry into the Nature and Causes of the Wealth of Nations" (1846/47), a obra de Pierre-Joseph Proudhon "Système des contradictions économiques ou Philosophie de la misère" foram, por fim, incluídas nos volumes IX e X (1847) ${ }^{1}$. Stirner tinha, também, empreendido o trabalho de traduzir as obras de Say e de Smith. Por outro lado, a obra "Contradictions économiques", escrita por Proudhon, foi traduzida por Wilhelm Jordan. A série de livros só possibilitou a satisfação da encomenda de uma obra; ainda assim, as obrigações normalmente exigidas por um editor seriam mais que claramente satisfeitas por parte de Stirner. A tradução da obra-prima de Smith por Stirner iria valer como referência por mais de meio século (Smith, 1910).

Com a publicação da série de obras, Stirner iria afirmar-se dentro da língua germânica como um divulgador importante do liberalismo económico. As obras de Smith e Say tinham já anteriormente sido sujeitas a tradução para o alemão, mas a combinação dos três grandes do liberalismo económico franco-inglês abriu novos olhares sobre uma análise pungente e um entendimento teórico das realidades económicas.

\section{Smith, Say e Proudhon}

Adam Smith, muitas vezes referido como o fundador do liberalismo económico, tem, na sua primeira obra publicada em 1776, uma visão racional do mundo, na qual ele se expressa contra superstições e mundividências românticas (Smith, 1910, Volume 2: 224). O seu "sistema simples da liberdade natural" entende-se tanto como um esboço contra a visão pré-moderna duma "ordem divina" (Smith, 1910, Volume 2: 69), no qual não há nenhum privilégio feudal na ordem proposta por Smith, nenhum favor no sentido de uma entidade corporativa e nenhumas limitações, da forma como tinha sido imposta no comércio externo pela política económica do mercantilismo (Smith, 1910, Volume 1: 76; Volume 2: 27 e seguintes). Assim, Smith apareceu como um representante do co-

\footnotetext{
${ }^{1}$ Mackay $(1977,254)$ e Helms $(1966,526)$ duvidavam que tivesse sido Stirner a publicar os dois últimos volumes da série. Ambos admitiram abertamente que uma parte do exemplar do livro sem o título da série, ou seja, só com as informações do escritor, fosse publicada no tradutor e editor. Contra a interpretação de Mackay e Helms está o facto de posteriormente também terem sido postos em circulação volumes com o título de série onde Stirner foi citado como editor pelo editor das Epigonen. (Wigand, Otto (1848): Epigonen, 5 Volume, Editora Otto Wigand Leipzig, citado em: Helms 1966, 526).
} 
mércio e das profissões livres. Central no seu pensamento estava o trabalho como factor de produção, que para ele era uma prova da "riqueza das Nações" (Smith, 1910, Volume 2: 154). Com isto, o filósofo moral escocês não só se evidenciou como um apologista do ensino moderno do valor do trabalho, como também acentuou, no mesmo contexto, o efeito produtivo da especialização industrial (Smith, 1910, Volume 1: 3). Smith não deixou dúvidas quanto às vantagens da propriedade privada, mas ao mesmo tempo também pôs em evidência alguns problemas existentes em relação à mesma. Em particular, Smith reconheceu uma fonte de exploração na propriedade da terra. "Por toda a parte, onde há muita riqueza", referiu Smith numa peroração, "também há uma grande desigualdade." (Smith, 1910, Volume 2: 172). Para Adam Smith, a super-abundância e a pobreza convivem em conjunto, e ele lamentava a "sede de possuir dos ricos" e discutia o tema do peso desigual entre propriedade empresarial e trabalhadores no que diz respeito às suas possibilidades para construírem relações económicas (Smith, Volume 1: 83; Volume 2: 172).

A obra de Jean Baptiste Say "Cours complet d'économie politique pratique", que foi publicada pela primeira vez no fim da década de 1820 , representou também um marco importante na história da teoria. A tradução inglesa da obra tornar-se-ia, no século XIX, na obra mais importante do curso de economia nos Estados Unidos da América, pelo menos até à eclosão da Guerra Civil. Como homem de negócios envolvido na vida económica, ao contrário de Smith que era um erudito universitário, Say aparecia em contradição relativamente a Smith em alguns pontos, coisa que também se traduzia na forma, que era mais incisiva (e muito mais motivada por interesses). Os ensinamentos de Smith sobre o valor do trabalho não foram acolhidos e prosseguidos por Say, pelo contrário, ele mostrou-se logo como um proponente e precursor do ensino do valor subjectivo (Say, 1845, Volume 1: 111), que no fim do século XIX iria encontrar acolhimento e se iria propagar. A propriedade privada aparecia no seu conjunto e dessa forma a Say como sendo digna de protecção, de tal forma que é intencionalmente que ele aceita os efeitos negativos da propriedade (Say, 1845, Volume 1: 215, 272, 292; Volume 2: 221, 232). No que diz respeito à formação de sindicatos de trabalhadores, Say representava uma corrente restritiva (Say, 1845, Volume 3: 69).

Completamente diferentes são as apreciações feitas pelos dois economistas Smith e Say relativamente às teses de Bernard Mandeville. No ano de 1714, Mandeville publicou a primeira versão de "The Fable of the Bees: or Private Vices Publick Benefits", na qual realçou os usos sociais do consumo vicioso. Aí está a descrição dele da "Colmeia", na qual conviviam numa sociedade dividida uns pobres trabalhadores sofrendo privações e uns ricos consumidores, vorazes exploradores. Uma forma de revolução cultural que traria os ricos de volta para a "Rota da virtude", 
apresentava-se, de acordo com Mandeville, nesta senda e para o conjunto da sociedade, como fatídico. As pretensões afundadas permitem que a produção se vá abaixo, com a consequência dum empobrecimento generalizado (Mandeville, 1998). Adam Smith critica na sua obra "The Theory of Moral Sentiments" o sistema de Mandeville nas suas "Tendências ... (como) completamente e totalmente pernicioso" (Adam Smith, citado em Schneider 2001: 114). Ele parte do princípio de que a acumulação de capital e aumento da riqueza da sociedade só se pode realizar com base no trabalho e na poupança, e não tinha para com actividades especulativas ou comportamentos socialmente insensíveis qualquer tipo de consideração. No entanto, completamente ao contrário, posicionava-se Say em relação a Mandeville (Say, 1845, Volume 1: 204), essencialmente menos constrangido por escrúpulos.

Quando, em 1846, Pierre-Joseph Proudhon publicava a sua obra "Contradictions économiques", já ele tinha granjeado para si próprio um nome enquanto crítico de Economia Política Clássica (Proudhon, 1998). A obra de Proudhon tratava dos sinais característicos de sociedades produtoras de bens de consumo, onde no centro das suas considerações estava o momento do desenvolvimento. A crítica de Proudhon colhe das teses de Thomas Robert Malthus que era notório por achar que a "mesa da natureza" não estava posta para o conjunto da humanidade, e que, partindo desta interpretação pesimista, prognosticava escassez alimentar e fome (Malthus, 1977, Proudhon, 2003: 68). Por outro lado, Proudhon entendia que estava na ordem do dia uma nova ordem social que alargaria as possibilidades de produção e distribuição, de forma que não só o princípio da liberdade, mas também o da igualdade e solidariedade na sociedade pudessem ser consolidados (Proudhon, 2003: 516). Com a hesitação em criar monopólios nos sectores produtivos, com um alargamento das margens de crédito ficou a questão da partilha desarmada (Proudhon, 2003: 519). As visões tradicionais de Ordem não podiam ter em relação a isso qualquer tipo de inibição, e o socialista francês elogiou expressamente neste contexto a crítica de Adam Smith à propriedade fundiária (Proudhon, 2003: 566).

Acima de tudo, desagradava a Proudhon a consideração pouco diferenciada que Say fazia do mercado de trabalho. O comportamento complexo do mercado de trabalho não é de maneira nenhuma comparável com aquele dos bens de consumo, como é notório em Say (Proudhon, 2003: 88). Aí, onde um exército de reserva industrial tem proporcionalmente uma fraca procura pelo factor de trabalho, está obrigatoriamente uma troca desigual, e há, portanto, um nível remuneratório mais baixo (Proudhon, 2003: 67). Proudhon identificou ainda outras máculas invisíveis da Economia Política - ele examinou, por exemplo, o contributo da racionalização técnica para o alargamento do desemprego (Proudhon, 
2003: 133), e também considerava que havia uma relação directa entre uma ordem competitiva imperfeita e a construção de monopólios (Proudhon, 2003: 159). Este socialista libertário escreveu persistentemente e com veemência contra a construção de monopólios. Por outro lado, também the era claro que o socialismo da época dele tinha que ser feito através duma inclusão mais forte da Economia Política, de forma a estar mais próximo da realidade.

Com a apresentação de conteúdo das obras de Say, Smith e Proudhon torna-se mais inteligível a série publicada sob a edição de Stirner, que à primeira vista poderá, porventura, parecer pouco comum. Poder-se-á concluir que, com base no manual de ensino de Jean Baptiste Say (1845), deveriam ser a seguir explicadas as doutrinas da economia contemporânea. A seguir é posta em contraste a visão com base no exposto pelo filósofo moral Adam Smith (1846/47), o qual, comparado com Say, representa ainda uma outra, e essencialmente mais branda variante do liberalismo económico. Uma visão redonda é dada, finalmente, pela junção da crítica contemporânea à Economia Política, como é o caso com Pierre-Joseph Proudhon (1847).

\section{Elementos da Economia Clássica nas obras de Stirner}

Existem vários indícios de que o desencanto do pensamento de Stirner com a Economia Política Clássica deixou marcas não desprezíveis.

- Assim desempenhava um papel importante para Stirner - ancorado no seu âmago aos Clássicos - o momento orientado pelo desenvolvimento. Não só a primeira parte da sua obra principal tem que ver essencialmente com a diferenciação histórica de épocas sucessivas, mas além disso também com a temática do fim da ordem feudal através da industrialização, onde ele já para além do estado moderno tecia considerações (EE: 21 e seguintes.).

- A abordagem do pensamento de Stirner é, de mais a mais, indiscutivelmente orientada para a produção. O processo produtivo é para ele a questão central, onde a produção é, por assim dizer, o pressuposto para o consumo. No ordenamento dos sectores individuais da economia aparecem claramente os negócios e o comércio por detrás da produção (Stirner, 1976c: 335).

- Já em antecipação fazia Stirner a distinção entre entradas de macro- (conjunto de condições económicas) e de microeconomia (teorias de economia doméstica) no âmbito das formas de explicação das teorias económicas. Ele considerava ambas, em princípio, justificadas, no entanto também via claramente os limites das 
mesmas: enquanto as considerações macroeconómicas escorregavam para a abstracção, as considerações microeconómicas, pelas suas semelhanças com a realidade económica, só retratavam uma parte da verdade (Stirner, 1976b: 317 e seguinte).

Stirner não seria, no entanto, Stirner, não tivesse ele submetido a "Sacralização" da Economia Política a uma crítica tão radical. Assim, ele examinou à lupa o conceito de propriedade, que era um ícone da economia burguesa. Ele considerava a propriedade privada como insustentável, pelo que o proprietário burguês enquanto "homem sem propriedade" tem de aparecer consequentemente como um "excluido de tudo". "Em vez de poder ter o mundo por propriedade", ajuizou Stirner, "nem sequer lhe pertence o ínfimo ponto sobre o qual ele anda às voltas." (EE: 196). Ao contrário de Proudhon, que reconheceu (implicitamente) a propriedade, e que ele estigmatizou como "Roubo ( $\mathrm{vol}$ )", propõe Stirner simplesmente retirar a propriedade da protecção jurídica prevista pela ordem pública: "Aquilo de que todos querem participar será retirado ao indivíduo isolado que o queira só para si, será transformado em bem comum. ... [p. e.] Se não quisermos deixar a terra aos proprietários de terras, mas apropriar-nos dela, associamo-nos para esse fim, formamos uma associação, uma societé que se fará proprietária dela; ... E podemos também retirar-lhes muitas outras propriedades, e não apenas terras, e fazer delas nossa propriedade, propriedade dos... conquistadores." (EE: 196 e seguinte.).

Em Stirner, à semelhança da crítica formulada por Adam Smith, o direito de dispor de terras teve um desenvolvimento posterior. Stirner via claramente que através da propriedade eram provocadas quedas de poder dentro da sociedade, onde ele diferenciava entre propriedade socialmente relevante e irrelevante e chegou, com isso, a uma abordagem prematura da teoria do valor acrescentado: "No regime burguês, os trabalhadores estão sempre nas mãos dos possidentes, ..., nas mãos dos capitalistas. $\mathrm{O}$ trabalhador não pode valorizar o seu trabalho na medida do valor que ele tem para quem dele desfruta." (EE: 95)². De maneira nenhuma está Stirner, no entanto, inclinado a considerar que os trabalhadores têm unicamente um papel de vítima. Ele afirma: "Os trabalhadores têm a mais gigantesca força nas mãos, e se um dia tomassem verdadeiramente consciência dela

${ }^{2}$ As seguintes considerações básicas tecidas por Adam Smith demonstram-se retrospectivamente determinantes em relação à construção de Stirner da sua teoria da exploração. Primeiro: Smith considera o trabalho dos produtores iminentes não só como uma forma especial de propriedade, mas também como a base de "toda a restante propriedade" (Smith 1910 Band 2, 71). Segundo: No sistema económico moderno não cabe na sua totalidade à pessoa produtora o resultado produzido pela produção do factor de trabalho, já que há que ter em conta também os descontos correspondentes ao preço da terra e rendimentos de capitais (Smith 1910 Volume 2, 28). 
e a usassem, nada se lhes poderia opor ..." (EE: 96). Neste contexto Stirner mostra-se como um apoiante incondicional das coligações de trabalhadores i.e. dos sindicatos de trabalhadores ${ }^{3}$ (EE: 213 e seguinte.). Também em relação aos elogios feitos às relações de mercado e ao princípio de concorrência, posiciona-se Stirner com grande distanciamento. "A livre concorrência não é, de facto, «livre»", diz Stirner, convencido, "porque me falta a coisa mesma que me permite entrar nela." (EE: 206 e seguinte). Um encontro olhos nos olhos entre os agentes da economia tornou-se impossível por causa da interposição de casos herdados e protegidos por lei. No lugar duma economia concorrencial deveria estar uma economia cooperativa (EE: 217).

\section{Apontamentos sobre os efeitos históricos das teses economicamente relevantes de Stirner}

$\mathrm{Na}$ literatura relacionada com os temas relevantes aparece por acaso a indicação duma ligação de Stirner com a escola alemã de comércio livre (Mackay 1977: 69 e seguintes; Helms, 1966: 306 e seguinte; Lichtschlag, 2003: 11-14). A ideia de comércio livre - após o caso das Corn Laws na Grã-Bretanha em 1846 e o respectivo efeito de redução de custos de vida - tinha-se tornado até meados do século muito popular por toda a Europa. Na Alemanha, o já mencionado Julius Faucher defendia, em conjunto com os Berlinen Freien e outros, a aplicação do princípio do comércio livre. Em 1846, Faucher fundou, juntamente com Heinrich Beta, John Prince-Smith e outros, a União Alemã pelo Comércio Livre, e trabalhou, para além disso, como secretário do liberal de Manchester, Richard Cobden, tendo sido também Presidente da Sociedade Berlinense para a Política Económica em 1860. O trabalho em conjunto de Stirner e Faucher no âmbito dos Berliner Freien permanece até hoje o único elemento conhecido que poderá indicar uma relação entre Stirner e a escola alemã de comércio livre. Uma atitude de verdadeira aproximação parece, no entanto, de excluir, já que os apologistas do comércio livre de meados do século deveriam aparecer, consideradas as suas expectativas, como uns obcecados por "fantasmas e fé cega". A sua visão do mundo não contemplava os vários níveis diferentes de desenvolvimento das economias nacionais em competição, e os seus ensinamentos de comércio livre eram considerados como sendo idealizações. De facto, a era do comércio livre

\footnotetext{
${ }^{3}$ O filósofo e sociólogo austríaco Max Adler vê no Einzige um retrato do proletariado que, reconhecendo os seus interesses "egoístas", começa a defender-se contra as exortações e esquemas de normas da sociedade capitalista burguesa. De acordo com a avaliação de Adler, Stirner vale não só como filósofo, mas também como sociólogo (Adler, 1992).
} 
no século XIX durou relativamente pouco. Durante a crise económica que se seguiu ao afundamento da bolsa de Vienna em 1873, as ideias de comércio livre perderam o seu interesse pelo mundo fora e durante muito tempo.

Substancialmente mais férteis pareciam as considerações adoptadas por Stirner no campo do liberalismo social. O liberalismo social aceitava a ordem de mercado como sendo uma casa, por assim dizer, que era imutável nos seus alicerces. Ao mesmo tempo e por outro lado, devia-se derivar uma influência da forma da arquitectura interior desta casa, de maneira a que se rompesse com estruturas tornadas obsoletas e se criassem "novos espaços"4. Concretamente, as alterações feitas ao direito de propriedade da terra, intervenções nos sistemas monetários ou inovações na área da segurança social (palavra-chave: rendimento mínimo), deveriam equilibrar os defeitos de uma economia de mercado capitalista. Um dos representantes principais do liberalismo social alemão, Franz Oppenheimer, menciona Stirner várias vezes no seu sistema sociológico - por vezes crítico, outras vezes benevolente (Oppenheimer, 1922a, Volume 1: 90, 302, 540, 694; Volume 2: 34, 113, 236 e seguinte, 719, 802). Ressalva-se a circunstância de que, onde Stirner tratou da problemática da posse da terra, Oppenheimer leva a uma solução. Com o programa da cooperativa de habitação ele desenvolveu um conceito próximo da prática para vencer o comportamento tido como típico dos sistemas capitalistas (Oppenheimer, 1922b). Existe também uma certa relação entre Stirner e Oppenheimer a propósito das suas propostas para uma organização autónoma da sociedade. Ambos consideram as hierarquias criadas pelo Estado como inoportunas, ambos acham o livre arbitrio um elemento central da vida humana em comum, o

${ }^{4}$ John Stuart Mill fazia parte dos representantes mais importantes do liberalismo social. Não mais do que um século depois de Adam Smith, Mill empreendeu a feitura de uma adaptação da Economia Política Clássica no sentido de um liberalismo social próprio (Mill, 1948). Mill via que, no final de uma teoria da evolução dos progressos sociais, havia um aumento constante de interdependências recíprocas no interior da sociedade, as quais representavam, uma tendência crescente na direcção do corporativismo. Ele está convencido que a preocupação com a manutenção e a consolidação do sistema de cooperação aumenta a disponibilidade dos agentes decisivos. O Leitmotiv de Mill está cheio de afirmações de justiça remunerativa e de justiça comutativa onde uma correcção posterior resultando do equilíbrio de mercado não é de excluir. No âmbito dos seus desentendimentos teóricos com a economia, Mill desenvolve a propensão para por em causa o rigor de leis económicas, coisa que se depreende da sua receptividade perante os sindicatos, e com isso demonstra um desprendimento para com as antigas teorias clássicas de remuneração. As propostas de Mill visavam a fundação de cooperativas através de sindicatos de trabalhadores, e assim ele também era por uma oferta pública de oportunidades de formação mais elevada, e daí induzir uma maior igualdade de oportunidades (Hauer, 1991: 224 e seguintes, 265 e seguintes). 
qual deve ser garantido, de acordo com Stirner, pelas sociedades e associações (uniões), e de acordo com Oppenheimer através da dita cidadania livre (Oppenheimer, 1990: 131).

Dentro do espectro do liberalismo social, os propósitos de Stirner também deram um impulso ao sistema monetário. Na sua obra-prima, Stirner descreve não só a função do dinheiro como um meio de dominação - "Há uma herança inseparável da velha moeda" (EE, 216) -, mas sugere para além do mais que se retire a confiança à ordem monetária existente, e com isso a sua razão de ser: "Se não vos deixardes pagar em dinheiro, ela fica arruinada, ... ele perde todo o seu valor" (EE, 216). Insatisfeito, Stirner defendeu a criação duma "nova moeda" (EE, 216). Com isto ele fez a relação com as ideias de emissão autónoma de moeda, as quais já Jean-Baptiste Say tinha esboçado no seu "Cours complet": "Todo o homem privado pode subscrever uma nota corrente e entregá-la como pagamento para um bem quando o vendedor a aceita em vez de dinheiro. Este vendedor pode, por sua vez, quando ele compra um outro bem, dar a nota como forma de pagamento. O segundo comprador pode, com o mesmo propósito, dar a mesma nota a um terceiro. E assim circula uma nota passada: ela serve aquele que quer vender, ela serve aqueloutro que quer comprar, ela desempenha o serviço de uma quantidade de moeda." (Say, 1845, Volume 2: 163).

$\mathrm{O}$ conceito de emissão autónoma de dinheiro caiu em terreno fértil mais do que noutro sítio nos Estados Unidos da América, após duas tentativas de erigir um banco central (1791 e 1817) terem fracassado. Nenhuma das duas instituições teve o efeito estabilizador que era esperado que tivessem sobre a vida económica, de tal forma que a função de emissão de moeda seria cada vez mais aproveitada por uma série diversa de bancos regionais. Ser dono de um banco e emitir moeda tornar-se-ia nos Estados Unidos da América quase numa espécie de direito fundamental. Até ao princípio do século XX só os pequenos bancos é que punham e dispunham, com o resultado admirável de que, em vésperas da Guerra Civil Americana, havia de 7.000 a 9.000 espécies diferentes de notas bancárias em circulação, emitidas por cerca de 1.500 institutos monetários (Galbraith 1978, 197 e seguinte.). A seguir à Guerra da Secessão seriam tomadas novamente iniciativas no sentido de unificar o sistema monetário, mas mesmo assim só foi finalmente fundado um banco central pouco antes do princípio da Primeira Guerra Mundial. O anarquista americano Benjamin R. Tucker (Tucker, 1976: 17), que contribuiu essencialmente para tornar o "Einzigen" conhecido nos Estados Unidos da América, elogiou as formas de emissão de moeda postas em prática no século XIX nos Estados Unidos da América: "A colocação em circulação de moeda tem de ser tão livre quanto a produção de sapatos." (Benjamin R. Tucker citado em Eltzbacher, 1977, 185). Na verdade faltava às activida- 
des de emissão de moeda um retoque final de fundamento teórico, embora pareça que o efeito dinamizador tenha, na prática, sido enorme. Logo no final do século XIX, os EUA apareciam como a nova potência e líder económico.

A "colocação em circulação de moeda nova" constituía também uma das ideias centrais no âmbito da Economia Livre (Gesell, 1949) fundada por Sílvio Gesell, a qual também é de relevo no espectro do liberalismo social $^{5}$ (Ramus, 2000: 97). A sua aproximação teorética ao essencial do sistema monetário no contexto do capitalismo moderno levou Gesell a reconhecer que o dinheiro não tinha tão só as funções dum meio de câmbio no qual residiam as unidades comuns de medida e os meios de conservação de valor, mas que a moeda era também responsável por diferenças de poder nas trocas económicas. Cada pessoa profissionalmente activa está sob obrigação de oferecer os seus serviços no mercado, nenhum profissional pode guardar as suas existências muito tempo sem sofrer perdas, só o proprietário ou representante do capital monetário tem um meio independente à sua disposição, o qual, de acordo com as necessidades, pode ser resgatado ou posto em uso. Erich Kästner levou no seu "Hino aos banqueiros" as circunstâncias ao limite: "Das Geld wird flüssig. Das Geld wird knapp. Sie machen das ganz nach Bedarf. Und schneiden den andern die Hälse ab. Papier ist manchmal scharf ..."6 (Kästner, 1946: 213).

O que é que, no entanto, se passa concretamente, de acordo com Gesell, nos acontecimentos económicos? O dinheiro, que é retirado do círculo económico, entenda-se, restrições no aparelho creditício, tornam o conjunto da vida económica mais propensas a crises, os investimentos permanecem baixos, o consumo fica adiado. Além disso, há que registar uma distribuição módica de resultados sérios, quando a escassez verificada do capital monetário, a "mais-valia monetária", i.e. a taxa de juro, sobe. Gesell propõe uma reforma do sistema monetário, a instituição de dinheiro livre, por assim dizer: Uma nova unidade monetária, que renuncia a toda a cobertura por metais nobres, deve perder regularmente uma parte determinada do seu valor facial, para que a posição de superioridade da moeda na economia seja quebrada. A circulação forçada provocada pela

\footnotetext{
${ }^{5}$ Sobre as convergências e divergências entre Stirner e Gesell ver Senft 1990, 39 e seguinte, 59 e seguinte, 64 e seguinte. De ressalvar é mais do que tudo no dado contexto a ideia de "União" formulada por Stirner que, com o movimento de economia livre como iniciativa civil de teoria monetária incitado por Gesell, teve um cunho verdadeiro.

6 "O dinheiro torna-se corrente. O dinheiro torna-se escasso. Eles fazem-no inteiramente por necessidade. E aos outros cortam-lhes o pescoço. O papel é muitas vezes aguçado..." (Kästner, 1946, 213).
} 
"perda de dinheiro" ajuda, de acordo com Gesell, a assegurar a estabilidade económica, a promover a formação de capital real e, finalmente, a neutralizar a "mais-valia monetária" (Gesell, 1949: 235 e seguintes).

Com o desenvolvimento de moedas complementares sobreviveu a ideia anterior de Say para além de Stirner, de Tucker até Gesell, da liberdade monetária até hoje, tendo agora um eco surpreendente (Bartussek, 2007). É de esperar que, por causa da crise financeira actual, os sistemas monetários regionais venham a experimentar estímulos adicionais. Moedas complementares são não só apropriadas para contrariar com dinheiro uma economia em penúria, como garantem também no âmbito local uma maior definição individual em muitos sectores. Por último, mas não de menor importância, as moedas complementares fazem parte dum valioso material intuitivo, que demonstra os conhecimentos surpreendentes que o olhar da história económica pode ter escondido dentro de si.

\section{Bibliografia}

Adler, Max (1992), Max Stirner und der moderne Sozialismus (1906), Wien: Edition Wilde Mischung Band 2. Monte Verita.

Bartussek, Ruth (2007), “'Die Alchemie des Geldes' - ein Ausflug in die Welt der Komplementärwährungen", in: Senft, Gerhard (Hrsg.): Zwischen Zeiten \& Unzeiten. Gedenkschrift für Ludwig Stadelmann 1917-2004, Leipzig: edition unica, 191-201.

Eltzbacher, Paul (1977), Der Anarchismus (1895), Berlin, Libertad.

Engels, Friedrich (1976), "Umrisse zu einer Kritik der Nationalökonomie" (1844), in: Marx, Karl und Friedrich Engels - Werke Band 1, Berlin (Ost): Dietz, 499-524.

Galbraith, John Kenneth (1978), Die Tyrannei der Umstände. Ursachen und Folgen unseres Zeitalters der Unsicherheit, Bern und München: Scherz.

Gesell, Silvio (1949), Die Natürliche Wirtschaftsordnung (1916), Lauf bei Nürnberg: Rudolf Zitzmann.

Hauer, Peter (1991), Leitbilder der Gerechtigkeit in den marktwirtschaftlichen Konzeptionen von Adam Smith, John Stuart Mill und Alfred Müller-Armack, Frankfurt/M, Bern, New York und Paris: Europäische Hochschulschriften Reihe 5, Volks- und Betriebswirtschaft 1208.

Helms, Hans G. (1966), Die Ideologie der anonymen Gesellschaft. Max Stirners "Einziger" und der Fortschritt des demokratischen Selbstbewußtseins vom Vormärz bis zur Bundesrepublik, Köln: DuMont Schauberg.

Hentschel, Volker (1975), Die deutschen Freihändler und der volkswirtschaftliche Kongress 1858 bis 1885,Stuttgart: Ernst Klett.

Kästner, Erich (1946), "Hymnus auf die Bankiers", in: Kästner, Erich: Bei Durchsicht meiner Bücher, Zürich: Atrium, 213. 
Lichtschlag, André F. (2003), "Stirner und der Anarcho-Kapitalismus", in: Der Einzige. Vierteljahresschrift des Max-Stirner-Archivs, Nr. 2 (22), hrsg. von Kurt W. Fleming. Leipzig, 3. Mai 2003 [159 n. St. E.], 11-14.

Mackay, John Henry (1977), Max Stirner: sein Leben und sein Werk (1897), Reprint der 3.Auflage, Freiburg/Br: Mackay-Gesellschaft.

Malthus, Thomas Robert (1977), Das Bevölkerungsgesetz (1798), München: Deutscher Taschenbuch Verlag, 1977.

Mandeville, Bernard (1998), Die Bienenfabel (1714), Frankfurt/M: Suhrkamp Verlag.

Marx, Karl (1968): "Ökonomisch-philosophische Manuskripte" (1844), in: Marx, Karl und Friedrich Engels, Werke, Ergänzungsband, 1. Teil, Berlin (Ost): Dietz, 465-588.

Mill, John Stuart (1948), Über die Freiheit (1859), Heidelberg: Freiheit.

Oppenheimer, Franz (1922a), System der Soziologie, Band 1 und 2, Jena: Gustav Fischer.

Oppenheimer, Franz (1922b): Die Siedlungsgenossenschaft. Versuch einer positiven Überwindung des Kommunismus durch Lösung des Genossenschaftsproblems und der Agrarfrage, Jena: G. Fischer.

Oppenheimer, Franz (1990): Der Staat. Eine soziologische Studie (1907), Archiv für Sozial- und Kulturgeschichte Band 2, Berlin: Libertad.

Proudhon, Pierre-Joseph (1998), Was ist das Eigentum? Erste Denkschrift (1840), Wien: Monte Verità.

Proudhon, Pierre-Joseph (2003), System der ökonomischen Widersprüche oder: Philosophie des Elends (1846), hrsg. von Lutz Roemheld und Gerhard Senft, Berlin: Karin Kramer.

Ramus, Pierre (2000), Erkenntnis und Befreiung. Konturen einer libertären Sozialverfassung, Wien, Monte Verità.

Say, Jean Baptiste (1845/46), "Ausführliches Lehrbuch der praktischen Politischen Ökonomie" (1828/30), in: Die Nationalökonomen der Franzosen und Engländer, hrsg. von Max Stirner, 1.-4. Band, Leipzig: Otto Wigand.

Schneider, Peter (2001), "Die Macht des Neides. Gesellschaftstheorie und Anthropologie bei Smith, Mandeville, Rousseau und Freud", in: Kursbuch Nr. 143, 111-122.

Senft, Gerhard (1990), Weder Kapitalismus noch Kommunismus. Silvio Gesell und das libertäre Modell der Freiwirtschaft, Archiv für Sozial- und Kulturgeschichte Band 3, Berlin, Libertad.

Smith, Adam (1910), Der Reichtum der Nationen (1776), nach der Übersetzung von Max Stirner, hrsg. von Heinrich Schmidt, 2 Bände, Leipzig: Alfred Kröner.

Stirner, Max (2004), O Único e a sua Propriedade, Tradução João Barrento e posfácio de José A. Bragança de Miranda, Lisboa: Antígona.

Stirner, Max (2009), Der Einzige und sein Eigentum. Ausführlich kommentierte Studienausgabe, hrsg. von Bernd Kast. Karl Alber, Freiburg/München. 
Stirner, Max (1976a), "Preußen”, in: Leipziger Allgemeine Zeitung, Nr. 173, 22. Juni 1842, wieder abgedruckt in: Stirner, Max, Kleinere Schriften und seine Entgegnungen auf die Kritik seines Werkes "Der Einzige und sein Eigentum", Faksimile-Neudruck der 2. Auflage Berlin 1914, hrsg. von John Henry Mackay. frommann-holzboog, Stuttgart-Bad Cannstatt, 122-125 .

Stirner, Max (1976b), "Der Kindersegen", in: Journal des oesterreichischen Lloyd, 22. Juli 1848, wieder abgedruckt in: Stirner, Max, Kleinere Schriften und seine Entgegnungen auf die Kritik seines Werkes "Der Einzige und sein Eigentum", Faksimile-Neudruck der 2. Auflage Berlin 1914, hrsg. von John Henry Mackay. frommann-holzboog, Stuttgart-Bad Cannstatt, 309-318.

Stirner, Max (1976c), "Bazar" in: Journal des oesterreichischen Lloyd, 24. September 1848, wieder abgedruckt in: Stirner, Max: Kleinere Schriften und seine Entgegnungen auf die Kritik seines Werkes "Der Einzige und sein Eigentum”, Faksimile-Neudruck der 2. Auflage Berlin 1914, hrsg. von John Henry Mackay. frommann-holzboog, Stuttgart-Bad Cannstatt, 333-336.

Tucker, Benjamin R. (1976): Staatssozialismus und Anarchismus (1888), Freiburg/Br: Mackay-Gesellschaft.

\section{RESUMO}

Johann Caspar Schmidt, conhecido entre o povo como Max Stirner, obteve um considerável prestígio como pedagogo, como crítico de cultura, e acima de tudo como filósofo do Vormärz alemão. Menos conhecido é, no entanto, que Stirner também foi tradutor e editor de obras importantes na área da economia, actividade na qual ele se evidenciou como conhecedor profundo da literatura sobre as teorias económicas da época em que vivia.

Um ponto de referência essencial de Stirner foi, durante os anos de 1840, o grupo dos Berliner Freien, que congregava a insatisfeita e protestativa elite intelectual. O grupo die Freien cultivava uma existência boémia e os seus membros distinguiam-se, antes de mais, por uma cultura radical de discussão; o representante da ideia do comércio livre, Julius Faucher, frequentava igualmente os Berliner Freien, que se debruçavam não só contra a repressiva situação política da época, mas também sobre novos rudimentos de teorias sociais, assim como abrangiam também movimentos sociais existentes. O movimento dos trabalhadores alemães iria também desempenhar um papel central neste contexto, movimento que deu os seus primeiros fortes sinais de vida com a revolta dos tecedores da Silésia em 1884. Como crítico particularmente radical apresentou-se Max Stirner. Ele considerava que várias formas de dominação de épocas anteriores estavam, na verdade, largamente ultrapassadas no tempo em que ele vivia, mas insistia na necessidade duma luta contra novas formas de dominação, ou seja, contra o sistema social e ideologias dominantes que subjugavam o Eu empírico. 


\begin{abstract}
MAX STIRNER AND THE CRITIQUE OF POLITICAL ECONOMY

Commonly known as Max Stirner, Johann Caspar Schmidt attained considerable recognition as pedagogue and culture critic, but most of all as a philosopher of the German Vormärz. However, it is a less known fact that Stirner was also a translator and publisher of important works in the domain of economy, an activity in which he distinguished himself for being a profound connoisseur of literature on economic theory of his own time.
\end{abstract}

Traduzido do Alemão por Manuel Martins de Oliveira. 